\title{
Tahap Profesionalisme Guru Agama dan Keberkesanannya di Maahad Muhammadi Perempuan, Kota Bharu, Kelantan, Malaysia ${ }^{1}$
}

\author{
Level of Professionalism of Religious Teachers and Its Impact in Maahad \\ Muhammadi Perempuan, Kota Bharu, Kelantan, Malaysia
}

\author{
MUTSALIM KHARENG*, ROHANEE MACHAE, HELOH KHAEKPHONG \& \\ JAFFARY AWANG ${ }^{2}$
}

\begin{abstract}
The professionalism of teaching is an important task that should be taken by every religious teacher. It is closely linked to the quality and excellence of teachers and students. This article aims to examine the level of professionalism among religious teachers of the Maahad Muhammadi (Girls), in Kota Bharu. To gather the information, this study used both qualitative and quantitative approaches. Qualitative data was gathered by using content analysis, while quantitative data was collected by distributing a survey of 57 respondents according to the Krejcie and Morgan schedule and interviews with school management committee members and school principals. The results of this study show that the teacher professionalism is at satisfied level while there is still room for improvement for interpersonal skills.
\end{abstract}

Keywords: education, interpersonal skills, learning management, religious education, teacher professionalism

Profesionalisme keguruan merupakan tugas mulia yang mempunyai hubungan rapat dengan kecemerlangan diri dan pembentukan kualiti hidup pelajar (Affrizal 2008). Menurut Trevor (2004), profesionalisme keguruan menuntut agar para guru berusaha menjana pengetahuan kepakaran diri. Council for Exception Children (CEC) menegaskan kod etika tentang nilai-nilai asas dan kepercayaan perlu ditekankan dalam kalangan para pekerja (Craig \& Barbara 2009). Profesionalisme keguruan (agama) harus dibina sebagai satu etika guru agama, kerana ia mempunyai hubungan rapat dengan kecemerlangan guru agama. Ia merujuk kepada sikap atau tingkah laku guru yang profesional dalam menyusun dan mengurus kerjayanya dalam hal pembelaan, pembaikpulihan, kerjasama, galakan, catatan lengkap, maklumat dan tindakan yang berasas dan sokongan terhadap pihak atasan (al-Hasyimi 1983). Guru agama yang profesional bukan hanya bertanggungjawab dalam menyampaikan proses pengajaran dan pembelajaran, bahkan memainkan peranan yang lebih dominan dalam merealisasikan hasrat pendidikan Islam.

\footnotetext{
1 A version of this article entitled "Pencapaian profesionalisme guru agama dan keberkesanan di Maahad Muhammadi Perempuan, Kota Bharu, Kelantan, Malaysia" has been previously published in Proceedings International Conference on Islam, Development and Social Harmony in Southeast Asia (ICDIS) 2019, authored by Mutsalim Khareng \& Rohanee Machae.

2 Mutsalim Khareng* (corresponding author), Ph.D., lecturer at Department of Islamic Studies, Academy of Islamic and Arabic Studies, Princess of Naradhiwas University, NARATHIWAT 96000, Thailand, email: habba_yabnee@hotmail.com; Rohanee Machae, Ph.D., lecturer at Department of Islamic Law, Academy of Islamic and Arabic Studies, Princess of Naradhiwas University, NARATHIWAT 96000, Thailand, email: nee_2750@hotmail.com; Cheloh Khaekphong, Ph.D., Dean of Academy of Islamic and Arabic Studies, Princess of Naradhiwas University, NARATHIWAT 96000, Thailand, e-mail: cheloh_ais@hotmail.com; Jaffary Awang, Ph.D., Director of Research Centre for Theology and Philosophy, Faculty of Islamic Studies, National University of Malaysia, 43600 BANGI, Malaysia, email: jaffary@ukm.edu.my.
} 
Lilia \& Norlela (2000) menjelaskan profesionalisme keguruan memainkan peranan penting dalam mengembangkan kemahiran dan membentuk akhlak pelajar serta guru sebagai perancang, pengurus, fasilitator, pembimbing dan tauladan kepada pelajar.

Untuk mencapai tahap profesionalisme guru yang sewajarnya, beberapa usaha harus dilaksanakan oleh para guru seperti mengembangkan iltizam secara berperingkat ke arah menjadi guru profesional sebagai kerjaya hidup. Pada masa yang sama, pelaburan dan penggunaan ilmu pengetahuan harus wujud agar dapat dimanfaatkan oleh pelajar pada setiap masa di samping menitikberatkan soal pertambahan pengetahuan profesionalisme dalam bidang ilmu yang lain (Goodson \& Pik 2008). 'Abd al-Hamid (1985) menyatakan lazimnya seorang dikatakan profesional jika ia mahir dalam bidang pekerjaannya di mana ia mendapatkan pencapaian hasil daripada ia bekerja. Justeru, kajian ini memfokuskan pencapaian profesionalisme keguruan guru Muslim yang berteraskan konsep 5M (Mudarris, Mu`allim, Murabbi, Muaddib dan Mursyid).

\section{Metodologi Kajian}

Kajian ini berbentuk tinjauan terhadap profesionalisme guru agama di Maahad Muhammadi Perempuan, Kota Bharu, Kelantan. Kajian ini mempunyai dua objektif iaitu pertama untuk mengenalpasti konsep profesionalisme guru agama dalam perspektif Islam melalui metode kualitatif. Manakala bagi objektif kedua, bertujuan untuk mengenalpasti tahap pencapaian profesionalisme guru agama di Maahad Muhammadi Perempuan. Rekabentuk kajian ini adalah berasaskan kaedah gabungan atau mixed method yang berpandukan kepada teori Frechtling \& Westat (1992) yang menyatakan: "Combining the two methods pays off in improved instrumentation for all data collection approaches and in sharpening the evaluator's understanding of findings". Pendekatan kuantitatif yang digunakan dalam kajian ini dilaksanakan melalui soal selidik dan temu bual. Dalam menggunakan pendekatan kuantitatif, pengkaji berpandukan kepada teori Oppenheim (1992) yang menyatakan bahawa soal selidik dan temu bual merupakan dua instrumen yang berkesan bagi mendapat maklumat daripada responden.

\section{Pembinaan Soal Selidik}

Soal selidik dibina berdasarkan kajian literature terhadap teori dan konsep profesionalisme guru agama dalam perspektif Islam. Soal selidik dalam kajian ini terbahagi kepada 6 bahagian. Bahagian A mengandungi 7 item yang berkaitan dengan maklumat latar belakang demografi iaitu jantina, tahap pendidikan, memiliki surat perakuan guru, umur, pengalaman bekerja, status perkahwinan dan kawasan tempat tinggal. Manakala bahagian $\mathrm{B}$, mengandungi 8 item melihat kemahiran berilmu pengetahuan, bahagian $\mathrm{C}$ mengandungi 8 item melihat kemahiran pengurusan pembelajaran, bahagian D mengandungi 8 item melihat kemahiran menyampai ilmu pengetahuan, bahagian E mengandungi 8 item melihat kemahiran menilai pembelajaran dan bahagian $\mathrm{F}$ mengandungi 8 item melihat interpersonal guru.

Berdasarkan kepada kajian tahap pencapaian profesionalisme guru agama dan keberkesanannya di Maahad Muhammadi Perempuan, maka pengkaji membina soal selidik dengan menyediakan pemilihan jawapan-jawapan berbentuk skala Likert. Kedudukan lima peringkat skala likert dari 1 hingga 5 seperti mana ternyata di dalam jadual berikut:

Jadual 1: Skala Likert dan Kedudukan Pemarkahan

\begin{tabular}{cl}
\hline Kedudukan Pemarkahan & \multicolumn{1}{c}{ Skala } \\
\hline 5 & Sangat setuju \\
4 & Setuju \\
3 & Sederhana \\
2 & Tidak setuju \\
1 & Sangat tidak setuju \\
\hline
\end{tabular}

Sumber: Adaptasi daripada Ahmad Sunawari (2011) 
Kesahan dan kebolehpercayaan instrumen soal selidik

Bagi tujuan kesahan dan kebolehpercayaan instrumen soal selidik, pengkaji berpandukan kepada beberapa rujukan seperti Chua (2006) dan Creswell (2008) tentang tiga proses kesahan instrumen iaitu kesahan kandungan, kesahan konstruk dan kesahan kriteria. Kesahan kandungan boleh dilakukan dengan dua bentuk iaitu dengan mendapat pandangan sekumpulan responden dan pakar dalam bidang berkenaan. Untuk instrumen soal selidik dalam kajian ini, kesahan kandungan (Content Validity) telah disemak oleh pakar-pakar terdiri 10 orang pensyarah pendidikan Islam di universiti-universiti di Selatan Thailand. Hasil semakan kesahan kandungan berada pada .80-1.00. Soal selidik diuji kebolehpercayaan (Reliability) ke atas 89 guru agama yang mengikuti program 'Memartabatkan Kualiti Guru Agama 2018'. Hasil ujian kebolehpercayaan soal selidik dapati berada pada .894 melebihi .6 dan ia boleh diterima.

\section{Sampel Kajian}

Jumlah guru agama di Maahad Muhammadi Perempuan adalah sebanyak 62 orang. Dalam kajian ini, pengkaji telah menggunakan kaedah pensampelan rawak mudah (Simple Random Sampling) ke atas 57 orang guru agama berdasarkan Jadual Krejcie and Morgan. Pemilihan teknik pensampelan rawak mudah dipilih oleh pengkaji kerana ia dapat mewakili keseluruhan guru agama di Maahad tersebut.

\section{Pengedaran Soal Selidik}

Setelah soal selidik disemak dan diubahsuai dalam proses semakan kesahan oleh pakar yang berkenaan dan ujian kebolehpercayaan instrumen kajian dengan kebenaran pengetua Maahad Muhammadi Perempuan. Setelah permohonan diizinkan, pengkaji menjalankan kajian lapangan melalui anjuran seminar kecil dengan berwacana tentang perkara-perkara berkaitan pengajaran di kalangan para guru agama. Soal selidik diedar secara langsung dan responden diberi peluang untuk menyoal sebarang kekeliruan terhadap soal selidik. Setelah semua soal selidik dikembalikan, pengkaji menjalankan semak semula ke atas semua set soal selidik untuk memastikan soal selidik diisi dengan lengkap dan sempurna. Kemudian maklumat dalam soal selidik dianalisis dengan menggunakan program SPSS 12. Dalam menginterpretasi dapatan deskriptif, pengkaji menggunakan jadual skala min yang diadaptasi dalam buku Analisis Data SPSS oleh Silcaru (2008). Skor-skor min dalam setiap dimensi telah disusun mengikut urutan menurun (decending) dari skor min paling tinggi hingga kepada skor min yang paling rendah sebagai mana dalam jadual 2 di bawah:

Jadual 2: Intepretasi Skor Min

\begin{tabular}{cll}
\hline \multicolumn{1}{c}{ Skor Min } & & \multicolumn{1}{c}{ Intepretasi } \\
\hline 4.51 hingga 5.00 & Amat Tinggi & \\
3.51 hingga 4.50 & Tinggi & \\
2.51 hingga 3.50 & Sederhana & \\
1.51 hingga 2.50 & Rendah & \\
1.00 hingga 1.50 & Amat Rendah \\
\hline
\end{tabular}

Sumber: Adaptasi daripada Silcaru (2008)

\section{Dapatan Kajian dan Perbincangan}

Hasil kajian dianalisis dalam empat aspek analisis deskriptif iaitu: berilmu pengetahuan, kemahiran pengurusan pembelajaran, kemahiran penyampaian ilmu pengetahuan dan kemahiran menilai pembelajaran serta analisis deskriptif kemahiran interpersonal guru. 


\section{Analisis Deskriptif Berilmu Pengetahuan}

Untuk menguji tahap pencapaian berilmu pengetahuan para guru agama di Maahad Muhammadi Perempuan, pengkaji membina konstruk berdasarkan kemahiran berilmu pengetahuan sebanyak 8 item soalan sebagaimana ditunjukkan dalam Jadual 3 di bawah:

Jadual 3: Taburan Skor Min Dan Sisihan Piawai Bagi Pencapaian Kemahiran Berilmu Pengetahuan

\begin{tabular}{|c|c|c|c|c|c|c|c|c|}
\hline \multirow[t]{2}{*}{ No. } & \multirow{2}{*}{ Item } & \multicolumn{5}{|c|}{ Kekerapan \& Peratusan (N=57) } & \multirow[t]{2}{*}{ Min\&SP } & \multirow[t]{2}{*}{ Int } \\
\hline & & STS & TS & KS & $\mathrm{S} \quad \mathrm{A}-1+1$ & AS & & \\
\hline 1 & $\begin{array}{l}\text { Anda mempunyai ilmu } \\
\text { pengetahuan dalam bidang } \\
\text { agama secara mendalam }\end{array}$ & - & 1.8 & 64.9 & 29.8 & 3.5 & $3.35 / 0.58$ & Sederhana \\
\hline 2 & $\begin{array}{l}\text { Anda mempunyai asas ilmu } \\
\text { pengetahuan selain } \\
\text { daripada bidang agama pada } \\
\text { tahap yang sederhana }\end{array}$ & - & 3.5 & 66.7 & 28.1 & 1.8 & $3.28 / 0.55$ & Sederhana \\
\hline 3 & $\begin{array}{l}\text { Anda berkonsisten dalam } \\
\text { menuntut ilmu dan } \\
\text { meningkatkan prestasi diri } \\
\text { secara berterusan }\end{array}$ & 1.8 & 1.8 & 26.3 & 57.9 & 12.3 & $3.77 / 0.75$ & Tinggi \\
\hline 4 & $\begin{array}{lr}\text { Anda berkebolehan } & \text { dalam } \\
\text { mempelajari } & \text { ilmu } \\
\text { pengetahuan } & \text { secara } \\
\text { sendirian } & \end{array}$ & - & 3.5 & 42.1 & 50.9 & 3.5 & $3.54 / 0.62$ & Tinggi \\
\hline 5 & $\begin{array}{l}\text { Anda mempunyai } \\
\text { kemahiran pengetahuan } \\
\text { dalam bidang psikologi } \\
\text { pembelajaran }\end{array}$ & - & 3.5 & 61.4 & 26.3 & 8.8 & $3.40 / 0.70$ & Sederhana \\
\hline 6 & $\begin{array}{l}\text { Anda seorang guru yang } \\
\text { mahir dalam teori dan } \\
\text { prinsip perguruan }\end{array}$ & 1.8 & 1.8 & 52.6 & 40.4 & 3.5 & $3.42 / 0.68$ & Sederhana \\
\hline 7 & $\begin{array}{lr}\text { Anda seorang } & \text { guru yang } \\
\text { memahami } & \text { matlamat } \\
\text { pengurusan } & \text { pembelajaran } \\
\text { dengan jelas } & \end{array}$ & - & 1.8 & 21.1 & 70.2 & 7.0 & $3.80 / 0.63$ & Tinggi \\
\hline 8 & $\begin{array}{l}\text { Anda mempunyai ilmu } \\
\text { pengetahuan } \\
\text { pengalaman dan } \\
\text { seorang guru agama pada } \\
\text { tahap yang baik }\end{array}$ & 1.8 & 1.8 & 38.6 & 52.6 & 5.3 & $3.57 / 0.70$ & Tinggi \\
\hline & Min Keseluruhan & & & & & & $3.51 / 0.65$ & Tinggi \\
\hline
\end{tabular}

Sumber: Pengkaji (2019)

Jadual 3 di atas menunjukkan lapan item tahap pencapaian berilmu pengetahuan di kalangan guru agama Maahad Muhammadi Perempuan, terdapat 4 item mencapai skor min pada tahap tinggi iaitu guru berkonsisten dalam menuntut ilmu dan meningkatkan prestasi diri secara berterusan ( $\min =3.77 / \mathrm{sp}=0.62$ ), guru berkebolehan dalam mempelajari ilmu pengetahuan secara sendirian $(\mathrm{min}=3.54 / \mathrm{sp}=0.75)$, seorang guru yang memahami matlamat pengurusan 
pembelajaran dengan jelas $(\min =3.80 / \mathrm{sp}=0.63)$, dan mempunyai ilmu pengetahuan dan pengalaman sebagai seorang guru agama pada tahap yang baik $(\min =3.57 / \mathrm{sp}=0.71)$. Selebihnya, terdapat 4 item mencapai skor min pada tahap sederhana iaitu guru mempunyai ilmu pengetahuan dalam bidang agama secara mendalam $(\min =3.35 / \mathrm{sp}=0.58)$, mempunyai asas ilmu pengetahuan selain daripada bidang agama pada tahap yang sederhana $(\mathrm{min}=3.28 / \mathrm{sp}=0.55)$, mempunyai kemahiran pengetahuan dalam bidang psikologi pembelajaran $(\min =3.40 / \mathrm{sp}=0.70)$, dan seorang guru yang mahir dalam teori dan prinsip perguruan $(\min =3.42 / \mathrm{sp}=0.68)$.

\section{Analisis Deskriptif Kemahiran Pengurusan Pembelajaran}

Untuk menguji tahap pencapaian kemahiran pengurusan pembelajaran para guru agama di Maahad Muhammadi Perempuan, pengkaji membina konstruk berdasarkan kemahiran pengurusan pembelajaran sebanyak 8 item soalan sebagai mana ditunjukkan dalam Jadual 4 di bawah:

Jadual 4 Taburan Skor Min dan Sisihan Piawai bagi Pencapaian Kemahiran Pengurusan Pembelajaran

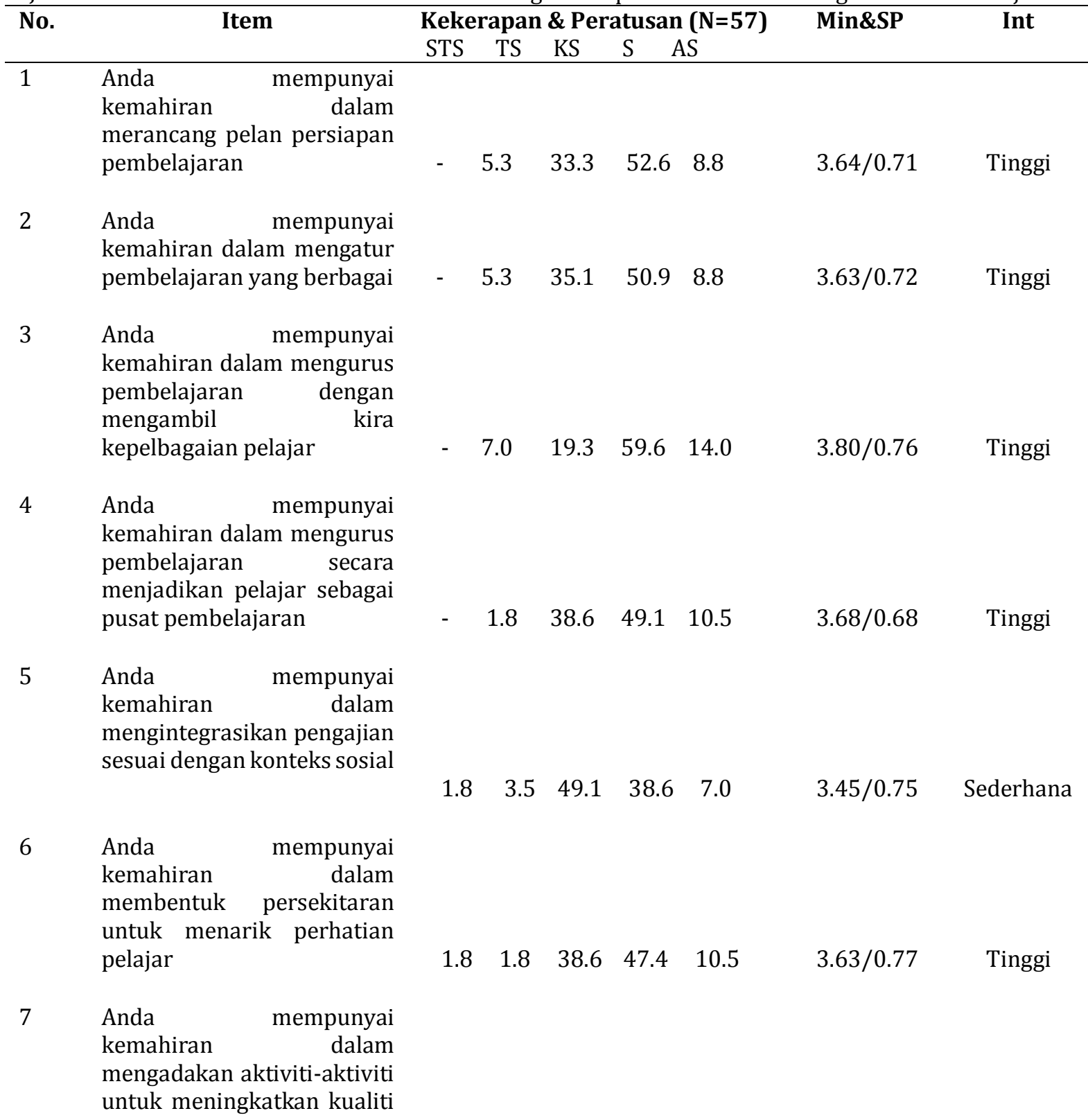




\begin{tabular}{|c|c|c|c|c|c|c|c|c|}
\hline & $\begin{array}{l}\text { pelajar mengikut hasrat } \\
\text { yang ditetapkan }\end{array}$ & & 3.5 & 40.4 & 47.4 & 8.8 & $3.61 / 0.70$ & Tinggi \\
\hline 8 & $\begin{array}{l}\text { Anda mempunyai } \\
\text { kemahiran dalam } \\
\text { mengintegrasikan } \\
\text { pembelajaran antara teori } \\
\text { dan praktik secara baik }\end{array}$ & - & 5.3 & 47.4 & 40.4 & 7.0 & $3.49 / 0.71$ & Sederhana \\
\hline & Min Keseluruhan & & & & & & $3.61 / 0.72$ & Tinggi \\
\hline
\end{tabular}

Sumber: Pengkaji (2019)

Jadual $4 \mathrm{di}$ atas menunjukkan lapan item tahap pencapaian kemahiran pengurusan pembelajaran di kalangan guru agama Maahad Muhammadi Perempuan, terdapat 6 item mencapai skor min pada tahap tinggi iaitu guru mempunyai kemahiran dalam merancang pelan persiapan pembelajaran $(\min =3.64 / \mathrm{sp}=0.71)$, guru mempunyai kemahiran dalam mengatur pembelajaran yang berbagai $(\mathrm{min}=3.63 / \mathrm{sp}=0.72)$, guru mempunyai kemahiran dalam mengurus pembelajaran dengan mengambil kira kepelbagaian pelajar $(\min =3.80 / \mathrm{sp}=0.76)$, mempunyai kemahiran dalam mengurus pembelajaran secara menjadikan pelajar sebagai pusat pembelajaran $(\mathrm{min}=3.68 / \mathrm{sp}=0.68)$, guru mempunyai kemahiran dalam membentuk persekitaran untuk menarik perhatian pelajar $(\min =3.63 / \mathrm{sp}=0.77)$ dan mempunyai kemahiran dalam mengadakan aktiviti-aktiviti untuk meningkatkan kualiti pelajar mengikut hasrat yang ditetapkan ( $\min =3.61 / \mathrm{sp}=0.70$ ). Selebihnya, terdapat 2 item yang mencapai skor min pada tahap sederhana iaitu mempunyai kemahiran dalam mengintegrasikan pengajian sesuai dengan konteks sosial $(\mathrm{min}=3.45 / \mathrm{sp}=0.75)$ dan mempunyai kemahiran dalam mengintegrasikan pembelajaran antara teori dan praktik secara baik $(\min =3.49 / \mathrm{sp}=0.71)$.

\section{Analisis Deskriptif Kemahiran Penyampaian Ilmu Pengetahuan}

Untuk menguji tahap pencapaian kemahiran penyampaian ilmu pengetahuan para guru agama di Maahad Muhammadi Perempuan, pengkaji membina konstruk berdasarkan kemahiran penyampaian ilmu pengetahuan sebanyak 8 item soalan sebagai mana ditunjukkan dalam jadual berikut:

Jadual 5: Taburan Skor Min dan Sisihan Piawai bagi Pencapaian Kemahiran Penyampaian Ilmu Pengetahuan

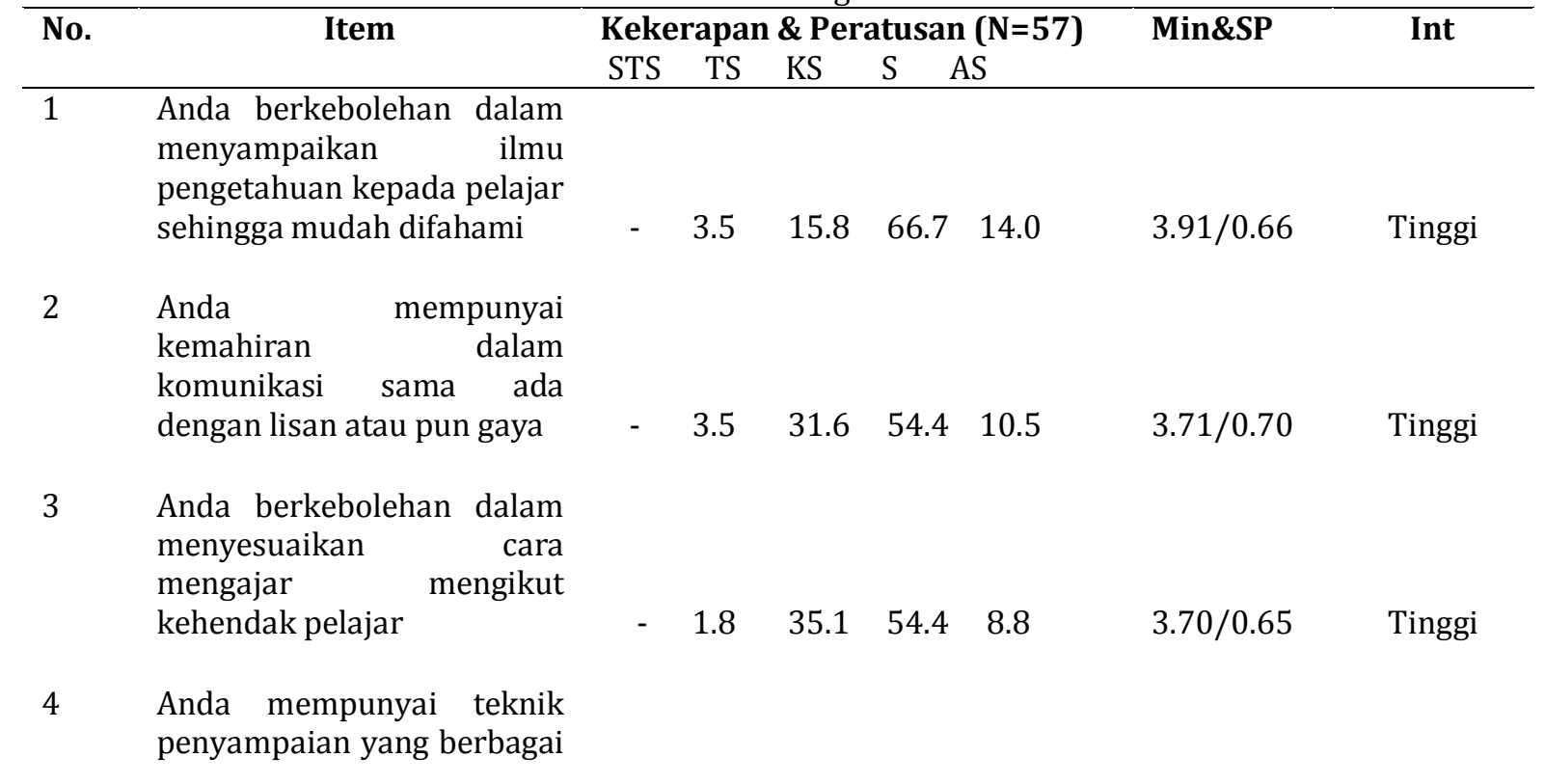


untuk menarik perhatian pelajar

Anda berkebolehan dalam menyampaikan ilmu pengetahuan kepada pelajar serta mereka mampu mengamalkan dalam kehidupan sehariannya

Anda berkebolehan dalam menggunakan teknik soal jawab dalam menyampaikan ilmu pengetahuan dan merangsangkan idea-idea

7 Anda mengajar secara memberi peluang kepada pelajar untuk menyoal dan kemukakan pandangan dengan beralasan

Anda melakukan adil ke atas setiap pelajar

Jadual 5 di atas menunjukkan lapan item tahap pencapaian kemahiran penyampaian ilmu pengetahuan di kalangan guru agama Maahad Muhammadi Perempuan, didapati semua 8 item mencapai skor min pada tahap tinggi iaitu guru berkebolehan dalam menyampaikan ilmu pengetahuan kepada pelajar sehingga mudah difahami ( $\min =3.91 / \mathrm{sp}=0.66)$, guru mempunyai kemahiran dalam komunikasi sama ada dengan lisan atau pun gaya $(\min =3.71 / \mathrm{sp}=0.70)$, guru berkebolehan dalam menyesuaikan cara mengajar mengikut kehendak pelajar ( $\min =3.70 / \mathrm{sp}=0.65)$, guru mempunyai teknik penyampaian yang berbagai untuk menarik perhatian pelajar $(\min =3.75 / \mathrm{sp}=0.76)$, guru berkebolehan dalam menyampaikan ilmu pengetahuan kepada pelajar serta mereka mampu mengamalkan dalam kehidupan sehariannya ( $\min =3.63 / \mathrm{sp}=0.58)$, berkebolehan dalam menggunakan teknik soal jawab dalam menyampaikan ilmu pengetahuan dan merangsangkan idea-idea ( $\min =3.77 / \mathrm{sp}=0.59$ ), guru mengajar secara memberi peluang kepada pelajar untuk menyoal dan kemukakan pandangan dengan beralasan $(\min =3.82 / \mathrm{sp}=0.71)$ dan guru melakukan adil ke atas setiap pelajar $(\min =3.77 / \mathrm{sp}=0.65)$.

\section{Analisis Deskriptif Kemahiran Menilai Pembelajaran}

Untuk menguji tahap pencapaian kemahiran menilai pembelajaran para guru agama di Maahad Muhammadi Perempuan, pengkaji membina konstruk berdasarkan kemahiran menilai pembelajaran sebanyak 8 item soalan sebagaimana ditunjukkan dalam Jadual di bawah:

Jadual 6: Taburan Skor Min dan Sisihan Piawai Bagi Pencapaian Kemahiran Menilai Pembelajaran

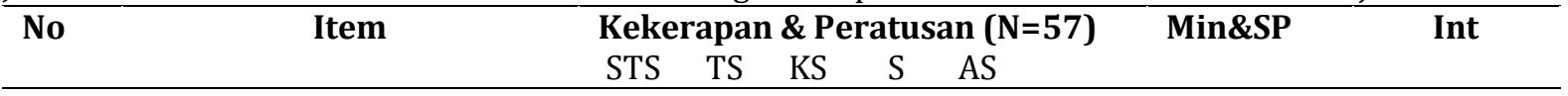




\begin{tabular}{|c|c|c|c|c|c|c|c|c|}
\hline 1 & $\begin{array}{lr}\text { Anda } & \text { mempunyai } \\
\text { pengetahuan } & \text { dan } \\
\text { memahami proses penilaian } \\
\text { pembelajaran }\end{array}$ & - & 1.8 & 33.3 & 59.6 & 5.3 & $3.68 / 0.60$ & Tingg \\
\hline 2 & $\begin{array}{l}\text { Anda mempunyai } \\
\text { kemahiran dalam menilai } \\
\text { pembelajaran dengan cara } \\
\text { yang berbagai }\end{array}$ & - & 1.8 & 42.1 & 50.9 & 5.3 & $3.59 / 0.62$ & Tingg \\
\hline 3 & $\begin{array}{ll}\text { Anda berkebolehan } & \text { dalam } \\
\text { membezakan } & \text { tahap } \\
\text { pengetahuan pelajar } & \end{array}$ & - & 3.5 & 21.1 & 64.9 & 10.5 & $3.82 / 0.65$ & Tingg \\
\hline 4 & $\begin{array}{lr}\text { Anda } & \text { mempunyai } \\
\text { kemahiran dalam } \\
\text { menyelesaikan masalah dan } \\
\text { menganalisis punca } \\
\text { permasalahan yang berlaku } \\
\text { dalam kelas dengan tepat }\end{array}$ & - & - & 40.4 & 52.6 & 7.0 & $3.66 / 0.60$ & Tingg \\
\hline 5 & $\begin{array}{l}\text { Anda berkebolehan dalam } \\
\text { mengubah teknik } \\
\text { penyampaian sesuai dengan } \\
\text { keadaan dalam bilik belajar }\end{array}$ & - & 3.5 & 24.6 & 59.6 & 12.3 & $3.80 / 0.69$ & Tingg \\
\hline 6 & $\begin{array}{lr}\text { Anda } & \text { memantau } \\
\text { perkembangan } & \text { dan } \\
\text { peningkatan pelajar secara } \\
\text { berterusan }\end{array}$ & - & 1.8 & 28.1 & 63.2 & 7.0 & $3.75 / 0.60$ & Tingg \\
\hline 7 & $\begin{array}{l}\text { Anda mengaturkan } \\
\text { pembelajaran berdasarkan } \\
\text { hasil penilaian anda }\end{array}$ & - & 3.5 & 35.1 & 56.1 & 5.3 & $3.63 / 0.64$ & Tingg \\
\hline 8 & $\begin{array}{l}\text { Anda berkebolehan dalam } \\
\text { meningkatkan prestasi } \\
\text { moral pelajar dengan cara } \\
\text { yang berbagai }\end{array}$ & - & 1.8 & 31.6 & 57.9 & 8.8 & $3.73 / 0.64$ & Tingg \\
\hline & Min Keseluruhan & & & & & & $3.70 / 0.66$ & Tingg \\
\hline
\end{tabular}

Jadual 6 di atas menunjukkan lapan item tahap pencapaian kemahiran menilai pembelajaran di kalangan guru agama Maahad Muhammdi Perempuan, didapati semua semua 8 item mencapai skor min pada tahap tinggi iaitu guru mempunyai pengetahuan dan memahami proses penilaian pembelajaran ( $\mathrm{min}=3.68 / \mathrm{sp}=0.60)$, guru mempunyai kemahiran dalam menilai pembelajaran dengan cara yang berbagai $(\min =3.59 / \mathrm{sp}=0.62)$, guru berkebolehan dalam membezakan tahap pengetahuan pelajar $(\min =3.82 / \mathrm{sp}=0.65)$, guru mempunyai kemahiran dalam menyelesaikan masalah dan menganalisis punca permasalahan yang berlaku dalam kelas dengan tepat $(\min =3.66 / \mathrm{sp}=0.60)$, guru berkebolehan dalam mengubah teknik penyampaian sesuai dengan keadaan dalam bilik belajar $(\mathrm{min}=3.80 / \mathrm{sp}=0.69)$, guru memantau perkembangan dan peningkatan pelajar secara berterusan $(\mathrm{min}=3.75 / \mathrm{sp}=0.60)$, guru mengaturkan pembelajaran berdasarkan hasil penilaian anda $(\min =3.63 / \mathrm{sp}=0.64)$ dan guru berkebolehan dalam meningkatkan prestasi moral pelajar dengan cara yang berbagai $(\mathrm{min}=3.73 / \mathrm{sp}=0.64)$. 


\section{Analisis Deskriptif Kemahiran Interpersonal Guru}

Untuk menguji tahap pencapaian kemahiran interpersonal guru di Maahad Muhammadi Perempuan, pengkaji membina konstruk berdasarkan kemahiran interpersonal guru sebanyak 8 item soalan sebagai mana ditunjukkan dalam Jadual berikut:

Jadual 7 Taburan Skor Min dan Sisihan Piawai bagi Pencapaian Interpersonal Guru

\begin{tabular}{|c|c|c|c|c|c|c|c|c|}
\hline \multirow[t]{2}{*}{ No } & \multirow[t]{2}{*}{ Item } & \multicolumn{5}{|c|}{ Kekerapan \& Peratusan $(\mathrm{N}=57)$} & \multirow[t]{2}{*}{ Min\&SP } & \multirow[t]{2}{*}{ Int } \\
\hline & & STS & TS & KS & $S \quad A$ & S & & \\
\hline 1 & $\begin{array}{l}\text { Anda adalah seorang yang } \\
\text { sopan dan sentiasa } \\
\text { menghormati orang lain }\end{array}$ & - & 1.8 & 15.8 & 54.4 & 28.1 & $4.08 / 0.71$ & Tinggi \\
\hline 2 & $\begin{array}{l}\text { Anda adalah seorang yang } \\
\text { menerima perbezaan } \\
\text { pendapat orang lain }\end{array}$ & - & 1.8 & 14.0 & 54.4 & 29.8 & $4.12 / 0.70$ & Tinggi \\
\hline 3 & $\begin{array}{l}\text { Anda sanggup bekerja } \\
\text { secara berpasukan }\end{array}$ & - & 1.8 & 7.0 & 54.4 & 36.8 & $4.19 / 0.69$ & Tinggi \\
\hline 4 & $\begin{array}{l}\text { Anda berkebolehan dalam } \\
\text { tukar fikiran bersama } \\
\text { dengan orang lain }\end{array}$ & - & 1.8 & 10.5 & 54.4 & 33.3 & $4.19 / 0.69$ & Tinggi \\
\hline 5 & $\begin{array}{l}\text { Anda bersedia } \\
\text { menjadi peserta } \\
\text { bekerjasama dalam } \\
\text { aktiviti sama ada dalam } \\
\text { sekolah, bersama dengan } \\
\text { ibu bapa mahu pun } \\
\text { masyarakat }\end{array}$ & - & - & 21.1 & 54.4 & 22.8 & $3.98 / 0.71$ & Tinggi \\
\hline 6 & $\begin{array}{l}\text { Anda seorang guru yang } \\
\text { berjiwa khidmat untuk } \\
\text { kepentingan masyarakat }\end{array}$ & - & 1.8 & 21.1 & 50.9 & 26.3 & $4.01 / 0.74$ & Tinggi \\
\hline 7 & $\begin{array}{l}\text { Anda mempunyai hubungan } \\
\text { baik dengan masyarakat }\end{array}$ & 1.8 & 1.8 & 17.5 & 52.6 & 26.3 & $4.00 / 0.82$ & Tinggi \\
\hline 8 & $\begin{array}{l}\text { Anda bersedia untuk } \\
\text { membantu rakan kerja }\end{array}$ & - & 1.8 & 8.8 & 56.1 & 33.3 & $4.19 / 0.74$ & Tinggi \\
\hline & Min Keseluruhan & & & & & & $4.10 / 0.73$ & Tinggi \\
\hline
\end{tabular}

Jadual 7 di atas menunjukkan lapan item tahap pencapaian kemahiran interpersonal guru di kalangan guru agama Maahad Muhammdi Perempuan, didapati semua 8 item mencapai skor min pada tahap tinggi iaitu guru adalah seorang yang sopan dan sentiasa menghormati orang lain ( $\min =4.08 / \mathrm{sp}=0.71)$, guru seorang yang menerima perbezaan pendapat orang lain $(\min =4.12 / \mathrm{sp}=0.70)$, sanggup bekerja secara berpasukan $(\mathrm{min}=4.19 / \mathrm{sp}=0.69)$, guru berkebolehan dalam tukar fikiran bersama dengan orang lain ( $\mathrm{min}=4.19 / \mathrm{sp}=0.69)$, guru bersedia untuk menjadi peserta dan bekerjasama dalam setiap aktiviti sama ada dalam sekolah, bersama dengan ibu bapa mahu pun masyarakat $(\min =3.98 / \mathrm{sp}=0.71)$, guru seorang guru yang berjiwa khidmat untuk kepentingan masyarakat $(\min =4.01 / \mathrm{sp}=0.74)$, mempunyai hubungan baik 
dengan masyarakat $(\min =4.00 / \mathrm{sp}=0.82)$ dan guru bersedia untuk membantu rakan kerja $(\min =4.19 / \mathrm{sp}=0.74)$.

\section{Berilmu Pengetahuan}

Berdasarkan kepada Jadual 3 di atas, 4 item mencapai skor min purata pada tahap yang tinggi. Ini menunjukkan majoriti guru agama di Maahad Muhammadi Perempuan berkonsisten dalam menuntut ilmu dan meningkatkan prestasi diri secara berterusan dan mereka berkebolehan dalam mempelajari ilmu pengetahuan secara sendirian serata memahami matlamat pengurusan pembelajaran dengan jelas dan mempunyai ilmu pengetahuan dan pengalaman sebagai seorang guru agama pada tahap yang baik. Menurut Scott (1999), maklumat merupakan satu badan yang objektif mengenai konsep-konsep dan item-item berkaitan yang menjadi tapak asas kepada pembinaan ilmu pengetahuan seseorang. Kajian Zulfahmi (2008) mendapati guru sangat penting menguasai matapelajaran.

Namun begitu, hasil kajian juga membuktikan bahawa sebahagian guru agama di Maahad Muhammdi Perempuan kurang berilmu pengetahuan dalam bidang agama secara mendalam dan tidak berkemahiran dalam bidang psikologi pembelajaran serta kurang berkemahiran dalam teori dan prinsip perguruan. Sesuai dengan dapatan Ee Ah Meng (1999) juga mendapati bahawa seseorang guru seharusnya menguasai matapelajaran yang diajar iaitu dengan tidak hanya menguasai segala tajuk-tajuk yang ada dalam sukatan pelajaran dan yang diperlukan untuk peperiksaan sahaja. Jadi, penguasaan ilmu pengetahuan di kalangan para guru agama sangat penting, malahan ilmu-ilmu tambahan yang lain seperti ilmu teknologi semasa, agar dapat selari dengan perubahan pendidikan moden.

\section{Kemahiran Pengurusan Pembelajaran}

Jadual 4 di atas secara keseluruhannya mendapati bahawa min purata keseluruhan berada pada tahap tinggi iaitu guru mempunyai kemahiran dalam merancang pelan persiapan pembelajaran, guru mempunyai kemahiran dalam mengatur pembelajaran yang berbagai, guru mempunyai kemahiran dalam mengurus pembelajaran dengan mengambil kira kepelbagaian pelajar, guru mempunyai kemahiran dalam mengurus pembelajaran dengan cara menjadikan pelajar sebagai pusat pembelajaran, guru mempunyai kemahiran dalam membentuk persekitaran untuk menarik perhatian pelajar dan guru mempunyai kemahiran dalam mengadakan aktiviti-aktiviti untuk meningkatkan kualiti pelajar mengikut hasrat yang ditetapkan. Namun terdapat 2 item yang berada pada tahap sederhana iaitu guru mempunyai kemahiran dalam mengintegrasikan pengajian sesuai dengan konteks sosial dan mempunyai kemahiran dalam mengintegrasikan pembelajaran antara teori dan praktik secara baik. Hasil tersebut cukup memberangsangkan pihak pengurusan Maahad Muhammadi Perempuan. Rancangan pelajaran mesti mempunyai objektif yang tepat, sesuai dengan isi pelajaran dan kesediaan latar belakang pelajar. Segala sumber dan alat bantu mengajar yang hendak digunakan hendaklah dipastikan berfungsi dengan baik supaya pelajar dapat menumpukan perhatian. Hal ini disokong oleh Yaakub (1994) yang mendapati guru harus bersedia menghadapi situasi mengajar dari segi mental dan fizikal untuk memastikan perjalanan pengajaran tersebut berjalan lancar dan dimanfaatkan dengan sepenuhnya oleh para guru. Kesediaan guru pelatih dalam aspek pengajaran disokong oleh Asmah (1989) yang menyatakan bahawa mereka bertindak sebagai fasilitator, pembimbing, pengurus, perancang, pengelola dan penilai di sekolah.

\section{Kemahiran Penyampaian Ilmu Pengetahuan}

Umumnya, Jadual 5 di atas menunjukkan min purata keseluruhan berada pada tahap tinggi. Ia merangkumi item guru berkebolehan dalam menyampaikan ilmu pengetahuan kepada pelajar 
sehingga mudah difahami, guru mempunyai kemahiran dalam komunikasi samada dengan lisan ataupun gaya, guru berkebolehan dalam menyesuaikan cara mengajar mengikut kehendak pelajar, guru mempunyai teknik penyempaian yang berbagai untuk menarik perhatian pelajar, guru berkebolehan dalam menyampaikan ilmu pengetahuan kepada pelajar serta mereka mampu mengamalkan dalam kehidupan sehariannya, berkebolehan dalam menggunakan teknik soal jawab dalam menyampaikan ilmu pengetahuan dan merangsangkan idea-idea, guru mengajar secara memberi peluang kepada pelajar untuk menyoal dan mengemukakan pandangan dengan beralasan, dan guru berlaku adil ke atas setiap pelajar. Ini menggambarkan para guru agama di Maahad Muhammadi Perempuan berkemahiran dalam menyampai ilmu pengetahuan sesuai dengan kehendak pelajar. Dapatan kajian Baharin (2012) menyatakan bahawa guru pada masa kini seharusnya tidak terhad kepada buku teks semata-mata. Ini kerana pelajar yang serius mahu gurunya memberi bahan-bahan pelajaran tambahan lain. Menurut Esah (2002), tidak ada satu pun kaedah ada kelebihan dan kekurangannya. Guru perlu melengkapkan diri mereka dengan pelbagai kemahiran mengajar sebelum menjalankan pengajaran dan pembelajaran agar pengajaran guru menjadi lebih menarik dan berkesan serta dapat menarik perhatian pelajar.

\section{Kemahiran Menilai Pembelajaran}

Manakala dalam Jadual 6 di atas, kajian menunjukkan min purata keseluruhan berada pada tahap tinggi. Ia merangkumi item guru mempunyai pengetahuan dan memahami proses penilaian pembelajaran, guru mempunyai kemahiran dalam menilai pembelajaran dengan cara yang berbagai, guru berkebolehan dalam membezakan tahap pengetahuan pelajar, guru mempunyai kemahiran dalam menyelesaikan masalah dan menganalisis punca permasalahan yang berlaku dalam kelas dengan tepat, guru berkebolehan dalam mengubah teknik penyampaian sesuai dengan keadaan dalam bilik belajar, guru memantau perkembangan dan peningkatan pelajar secara berterusan, guru mengaturkan pembelajaran berdasarkan hasil penilaiannya dan guru berkebolehan dalam meningkatkan prestasi moral pelajar dengan cara yang berbagai. Hasil kajian seperti ini, menggambarkan bahawa para guru agama di Maahad Muhammadi Perempuan memiliki kemahiran menilai pelajar pada tahap yang memberangsangkan. Pada masa yang sama, para guru perlu membantu pelajar untuk membuat yang terbaik dalam membuat tugasan, di samping sentiasa memberi semangat dan tambah keyakinan dalam diri pelajar dan menjauhi sebarang penilaian yang boleh menghilangkan kerjasama di antara pelajar. Para guru harus menilai sendiri terhadap sistem penilaian yang digunakan sejauhmana ia berkesan dengan pelajar. Kaedah penilaian seperti ini selari dengan kajian oleh Kamarul Azmi et al. (n.d).

\section{Interpersonal Guru}

Jadual 7 pula menunjukkan min purata keseluruhan berada pada tahap tinggi. Ia merangkumi item menjadi seorang yang sopan dan sentiasa menghormati orang lain, menjadi seorang yang menerima perbezaan pendapat orang lain, sanggup bekerja secara berpasukan, menjadi guru berkebolehan dalam tukar fikiran bersama dengan orang lain, menjadi guru bersedia untuk menjadi peserta dan bekerjasama dalam setiap aktiviti samada dalam sekolah, bersama dengan ibu bapa mahupun masyarakat, menjadi seorang guru yang berjiwa khidmat untuk kepentingan masyarakat, mempunyai hubungan baik dengan masyarakat dan menjadi guru yang bersedia untuk membantu rakan kerja. Dapatan demikian selari dengan dapatan kajian Mohd Safiee et al. (2008) di sekolah menengah teknik Melaka menunjukkan tahap interpersonal guru yang tinggi yang dikaitkan secara langsung dengan moral dan amalan positif.

Hasil kajian turut menggambarkan para guru agama mempunyai kesedaran bersosial dan komunikasi pada tahap yang baik. Ia memberi gambaran bahawa para guru sentiasa menekankan usaha ke arah mewujudkan kasih sayang antara satu sama lain. Secara rumusannya, dapatan kajian memberikan satu dimensi baru dalam usaha guru-guru untuk meningkatkan 
keberkesanan pengajaran dan pembelajaran dengan mengaplikasikan kemahiran interpersonal dalam konteks pelajar pintar cerdas. Tahap kemahiran interpersonal dalam kalangan guru masih mempunyai ruang untuk dipertingkatkan. Dalam konteks pelajar pintar cerdas, peningkatan amalan kemahiran interpersonal ini perlu mengambil kira keperluan pelajar yang unik dan berbeza.

\section{References}

Affrizal Ahmad. 2008. Kepentingan pendidikan dalam pembentukan kualiti hidup sejahtera. Malaysia Education Dean's Council Journal 2(Disember): 1-11.

Ahmad Sunawari Long. 2011. Pengenalan Metodologi Penyelidikan Pengajian Islam. Bangi: Universiti Kebangsaan Malaysia.

Asmah Omar. 1989. Kaedah Pengajaran Bahasa. Kuala Lumpur: Dewan Bahasa Dan Pustaka.

Baharin Abu \& Hasnita Ismail @ Nawang. 2012. Tahap Kesediaan Guru Pelatih Ijazah Sarjana Muda Teknologi Serta Pendidikan Kemahiran Hidup Mengajar Subjek Kemahiran Hidup Di Sekolah Menengah. Skudai: Fakulti Pendidikan Universiti Teknologi Malaysia.

Craig, R. Fiedler \& Barbara, Van Haren. 2009. A comparison of special education administrators' and teachers' knowledge and application of ethics and professional standards. The Journal of Special Education 43(3): 160-173.

Creswell, J.W. 2008. Education Research: Planning, Conduction and Evaluating Quantitative and Qualitative Research. New Jersey: Pearson Education, Inc.

Chua, Y.P. 2006. Kaedah dan Statistik Penyelidikan: Kaedah Penyelidikan Buku 1. Kuala Lumpur: McGraw Hill Education.

Ee Ah Meng, 1999. Pendidikan di Malaysia II. Cetakan Kedua. Shah Alam: Fajar Bakti Sdn. Bhd.

Esah Sulaiman, 2002. Amalan Profesionalisme Perguruan. Skudai: UniversitiTeknologi Malaysia.

Frechtling, S. \& Westat. 1997. User-Friendly Handbook for Mixed Method Evaluations. Arlington VA: National Science Foundation.

Goodson, I. \& Pik, L.C. 2008. Life history and collective memory as methodological strategies: studying teacher professionalisme. Teacher Education Quarterly 35(2, Spring): 5-28.

al-Hasyimi, Muhammad Ali. 1983. Syakhsiyyah al-Muslim. Beirut: Dar al-Quran al-Karim.

Kamarul Azmi Jasmi, Siti Hanim Naim \& Hilman Muhamad. n.d. Kaedah Penilaian Pengajaran dan Pembelajaran Pendidikan Islam. Johor: Universiti Teknologi Malaysia.

Lilia Halim \& Norlena Salamuddin. 2000. Orientasi akademik: pendekatan alternatif dalam program pendidikan guru siswazah di Malaysia. Akademika 56(1): 47-64.

Mohd Safiee Idris, Ashari Sikor, Siti Zahara Mohd Ariff, Mohd Zaid Mustafa, Ahmad Rizal Madar \& Latifah Md. Ariffine. 2008. Komunikasi interpersonal dalam pengajaran di kalangan guruguru teknikal sekolah menengah teknik di negeri Melaka. Conference paper. Persidangan Pembangunan Pelajar Peringkat Kebangsaan. Universiti Teknologi Malaysia.

al-Mursi, 'Abd al-Hamid. 1985. al-Syakhsiyah al-Muntajah. Mesir: Maktabah Wahbah.

Oppenheim, A. N. 1992. Questionaire Design, Interviewing and Attitude Measurement. Edisi 2. London: Printer Publishers.

Scott, T.E. 1999. Knowledge. In. Runco, M.A \& Pritzer, S.R. (ed.). Encyclopedia of Creativity, pp. 119129. New York: Academic Press.

Silcaru, T. 2008. Analisis Statistik SPSS. Nontaburi: S.R. Printing Mass Produk Sdn. Bhd.

Yaakub Isa. 1994. Guru Yang Efektif. Pahang: Jabatan Pendidikan Pahang.

Zulfahmi MD Hanafiah. 2008. Faktor-faktor yang mendorong keberkesanan pengajaran guru pelatih UTM dalam menghadapi latihan mengajar. Latihan Ilmiah. Universiti Teknologi Malaysia, Johor. 